\title{
Overexpression of the gene for Rpb7 subunit of yeast RNA polymerase II rescues the phenotypes associated with absence of the largest, nonessential subunit Rpb4
}

\author{
NIMISHA SHARMA and PARAG P. SADHALE* \\ Department of Microbiology and Cell Biology, Indian Institute of Science, Bangalore 560012, India
}

\begin{abstract}
The easily dissociable subcomplex of Rpb4 and Rpb7 subunits of yeast RNA polymerase II has been considered, for long, to play a role in stabilizing Pol II under stress. On the basis of previous genetic and biochemical observations, it was proposed that within the subcomplex one of the functions of Rpb4p is to stabilize the interaction between Rpb7p and the rest of Pol II. We took a direct approach to test the latter possibility by overexpression and mutagenesis of $R P B 7$ in absence of Rpb4p. We report here the results, which support the latter hypothesis. While it has been previously reported that absence of Rpb4p results in reduction in overall transcription by Pol II, our comparative analysis of RNAs from $R P B 4$ and $r p b 4 \Delta$ cells suggests that there are indeed several genes differentially expressed between the two cells. We propose that the qualitative differences in overall transcription in presence and absence of Rpb4p imply a more active role for Rpb4p in transcription of at least a subset of genes.
\end{abstract}

[Sharma N. and Sadhale P. P. 1999 Overexpression of the gene for Rpb7 subunit of yeast RNA polymerase II rescues the phenotypes associated with absence of the largest, nonessential subunit Rpb4. J. Genet. 78, 149-156]

\section{Introduction}

The transcription machinery that is responsible for expression of protein coding genes is comprised of the core RNA polymerase II, the general transcription factors, the coactivator/mediator complexes, and a myriad of specific regulators (Hampsey 1998; Ishihama et al. 1998). The genespecific regulators relaying the signals to the basal transcription machinery in response to changes in internal and external stimuli effect differential gene expression. The 12 core subunits of Pol II have been considered, until recently, to be responsible for carrying out the basic biochemical reactions involved in transcription, to confer stability on the core complex, and of course to provide surface for interaction with the general transcription factors (GTFs). The GTFs in turn mediate various promoterspecific interactions and help in recruitment of the basic transcription machinery to the promoter. Only recently has it been realized that one of the smaller Pol II core subunits,

*For correspondence. E-mail: pps@ mcbl.iisc.ernet.in.
Rpb5, could differentially affect expression of a certain subset of genes and thus play a regulatory role (Miyao and Woychik 1998). The question that needs to be addressed now is whether other components of the core polymerase may also be able to cause differential gene expression through direct or indirect interactions with gene-specific regulators.

The subcomplex within the yeast RNA Pol II, comprised of Rpb4p and Rpb7p, has been implicated in stress response in yeast (Woychik and Young 1989; Choder 1993; Choder and Young 1993). It was originally observed that the $r p b 4 \Delta$ mutant showed several conditional phenotypes. These include high-temperature as well as low-temperature sensitivity and inability to grow in inositol-deficient media (Woychik and Young 1989). Deletion of RPB4 is known to cause loss of resistance to various other stress conditions while overexpression of $R P B 7$ is known to enhance certain starvationspecific phenotypes (Woychik and Young 1989; Khazak et al. 1995). The Pol II purified from $r p b 4 \Delta$ cells as well as that from a mutant in the largest subunit of Pol II in yeast were shown to lack the two subunits Rpb4 and Rpb7 (Ruet et al. 1980; Edwards et al. 1991). This Rpb4p-deficient

Keywords. S. cerevisiae; stress response; transcriptional regulation; RNA polymerase II core subunits; RPB4; RPB7. 
Pol II was shown to be defective in promoter-specific transcription initiation. These observations have led to various hypotheses explaining the role of the two subunits, and the one that suggests that Rpb4p somehow stabilizes Pol II under stress conditions has been favoured (Mckune et al. 1993). During preparation of this manuscript a report was published showing that multicopy expression of $R P B 7$ rescues the rpb4 $\Delta$-associated stress phenotypes (Sheffer et al. 1999).

Here we report that rather than stabilizing Pol II under stress, Rpb4 is required for stable interaction of the polymerase with Rpb7p even under moderate conditions. By genetic analyses, we have shown that overexpression of $R P B 7$ or relatively low-level expression of dominant mutants of $R P B 7$ rescue the $r p b 4 \Delta$ deletion phenotypes. We present the relevance of these observations in the light of earlier published reports, which suggested stressresponse-specific role of $\mathrm{Rpb} 4$.

\section{Materials and methods}

General methods: Standard protocols were followed for mating of yeast (Saccharomyces cerevisiae) strains, sporulation tetrad dissection, plasmid segregation, etc. (Sherman et al. 1983; Ausubel et al. 1990). The yeast transformations were carried out by a modified lithium acetate method that does not involve heat shock of the yeast cells (Elble 1992). Denaturing polyacrylamide gels for analysis of the RNA arbitrary primed (RAP) PCR products were prepared and run as described in Ausubel et al. (1990). All the plasmids were transformed, amplified and manipulated in Escherichia coli DH5 $\alpha$. The manipulations of DNA were carried out as described in Ausubel et al. (1990).

Media: Yeast cells were grown in either YP (1\% yeast extract, $2 \%$ peptone) with $2 \%$ glucose or galactose as the carbon source or in synthetic minimal medium $(0.67 \%$ yeast nitrogen base without amino acids) with the desired supple- ments and either $2 \%$ glucose or $2 \%$ galactose as carbon source (Sherman et al. 1983).

Strains and plasmids: The yeast strains and plasmids used in this study are described in tables 1 and 2 respectively. The results presented here were originally observed in the SY5 strain and reproduced in the SY10 strain, which was derived from SY5 crossed with SY6210.

PCR mutagenesis: The basic mutagenic PCR was carried out as described by Sadhale and Woychik (1994). The RPB7 gene fragment in the plasmid pPS25 was PCR-amplified in presence of $\mathrm{MnCl}_{2}$ and various concentrations of $\mathrm{MgCl}_{2}$ between 0.5 and $2.0 \mathrm{mM}$. The PCR products were pooled and introduced along with equimolar amounts of a gapped plasmid, pBP86, into the SY5 strain (tables 1 and 2). The transformants were screened at $34^{\circ} \mathrm{C}$ and $37^{\circ} \mathrm{C}$ and further characterized in the SY10 strain.

Assay for temperature sensitivity: All strains were first streaked on solid synthetic minimal medium containing either $2 \%$ glucose or $2 \%$ galactose $+1 \%$ xylose as carbon source (Ausubel et al. 1990). Cells were harvested and suspended in water and spotted at comparable densities. In all experiments described below, the pre-inoculum was always in a medium containing glucose, and the cells were pelleted, washed and resuspended in the medium containing the respective sugar. To test temperature sensitivity the replica plates were incubated at $22^{\circ} \mathrm{C}, 34^{\circ} \mathrm{C}$ or $37^{\circ} \mathrm{C}$ for three days before photography.

Growth characteristics of the yeast strains: Five-ml pre-cultures were grown till mid-log phase at $22^{\circ} \mathrm{C}$ and then subcultured into $50 \mathrm{ml}$ of appropriate media at approximately $A_{600}=0.05$. They were maintained under shaking conditions $(100 \mathrm{rpm})$ at $22^{\circ} \mathrm{C}, 34^{\circ} \mathrm{C}$ and $37^{\circ} \mathrm{C}$. Cell density was monitored by measuring absorbance at $600 \mathrm{~nm}$. The morphological alterations were monitored by microscopic observations using an Olympus BX-50 microscope with Nomarski optics at

Table 1. List of plasmids.

\begin{tabular}{|c|c|c|c|}
\hline Plasmid & Description & $\begin{array}{l}\text { Copy number } \\
\text { per cell }\end{array}$ & Reference \\
\hline pPS24 & pJH359 & $\sim 50$ & Scafe et al. 1990 \\
\hline pPS5 & YEplac181 & $\sim 50$ & Geitz and Sugino 1988 \\
\hline pPS2 & YCplac111 & $1-2$ & Geitz and Sugino 1988 \\
\hline pPS12 & pYES2 & $\sim 50$ & Invitrogen, USA \\
\hline pPS25 & $R P B 4$ gene in pPS5 & $\sim 50$ & Sadhale and Woychik 1994 \\
\hline pBP86 & $\begin{array}{l}R P B 7 \text { gene in which the open reading frame is } \\
\text { replaced by HindIII restriction site }\end{array}$ & $1-2$ & This work \\
\hline pNS114 & BamHI-SalI fragment from pPS25 subcloned into pPS2 & $\sim 50$ & This work \\
\hline pPS40 & $R P B 4$ ORF cloned under the $G A L 1$ promoter in the pPS 12 vector & $\sim 50$ & This work \\
\hline pRA56 & 1.4-kb BamHI-SalI fragment containing $R P B 7$ gene in pPS2 & $1-2$ & This work \\
\hline pPS26 & 1.4-kb BamHI-SalI fragment containing RPB7 gene in pPS5 & $\sim 50$ & Sadhale and Woychik 1994 \\
\hline pPS41 & $R P B 7$ ORF cloned in the pPS 12 vector under the $G A L 1$ promoter & $\sim 50$ & This work \\
\hline
\end{tabular}


RNA Pol II core subunit levels regulate yeast gene expression

Table 2. List of strains.

\begin{tabular}{|c|c|c|}
\hline Name & Genotype/description & Reference/source \\
\hline SY5 & 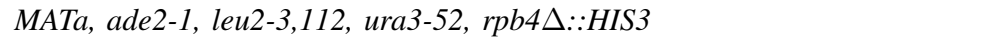 & Woychik and Young 1989 \\
\hline SY6210 & MAT $\alpha$, ade2-1, his $3 \Delta 200$, leu2-3,112, lys $2-801$, trp $1 \Delta 901$, ura3-52 & Vijayraghavan et al. 1989 \\
\hline $\mathrm{SY} 5 \times \mathrm{SY} 6210$ & 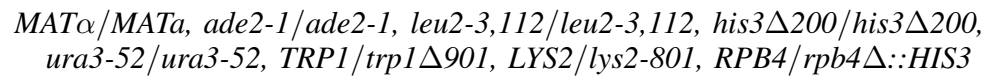 & This work \\
\hline SY10 & $\begin{array}{l}\text { MATa, leu2-3,112, lys } 2, \text { ura3-52, rpb4 } \Delta:: H I S 3 \\
\quad \text { (a segregant of the SY5 } \times \text { SY6210 cross) }\end{array}$ & This work \\
\hline SY101 & 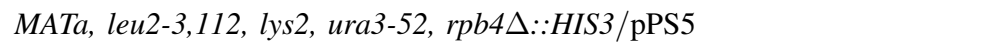 & This work \\
\hline SY102 & 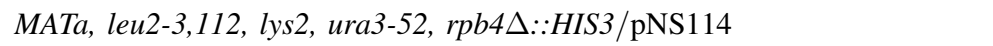 & This work \\
\hline SY103 & 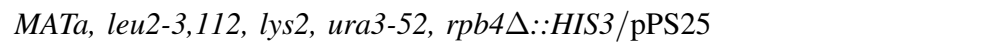 & This work \\
\hline SY104 & 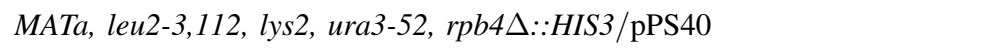 & This work \\
\hline SY105 & 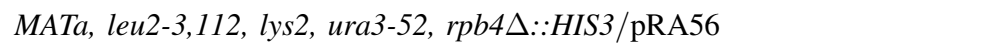 & This work \\
\hline SY106 & 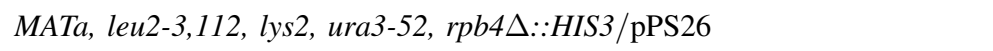 & This work \\
\hline SY107 & MATa, leu2-3,112, lys 2, ura3-52, rpb4 $\Delta:: H I S 3 / p P S 41$ & This work \\
\hline SY11 & $\begin{array}{l}\text { MATo, leu2-3,112, lys } 2, \operatorname{trp} 1 \Delta 901, \text { ura3 }-52, \operatorname{rpb} 4 \Delta:: H I S 3 \\
\quad \text { (a segregant of the SY5 } \times \text { SY } 6210 \text { cross) }\end{array}$ & This work \\
\hline
\end{tabular}

two-hour intervals for 36 hours. Photographs were taken at time points that showed significant alterations.

RNA isolation and analysis of transcriptional pattern: Total yeast RNA was isolated from $r p b 4 \Delta$ strains containing different numbers of copies of $R P B 7$ as described (Vijayraghavan et al. 1989). The analysis of the transcriptional pattern was carried out by performing RAP-PCR on total RNA isolated from different yeast strains. The RAPPCR was carried out using the RAP-PCR kit (Cat. \# 200440) from Stratagene according to manufacturer's instructions.

\section{Results}

\section{Overexpression of $\mathrm{RPB} 7$ rescues the rpb4 $\triangle$ defect in a dosage- dependent manner}

We proposed that in wild-type yeast interaction between $\mathrm{Rpb} 7 \mathrm{p}$ and the rest of the polymerase, which is inherently weak, is stabilized by Rpb4p. We have schematically depicted this in figure 1 (top panel). The second panel depicts the corollary that in the $r p b 4 \Delta$ mutant Rpb7p tends to dissociate from the rest of the polymerase and this leads to significant reduction in transcription. Thus the conditional phenotypes observed in absence of Rpb4p can be the result of the transcriptional defects due to this unstable interaction (Mckune et al. 1993). One can extrapolate from the above that under these conditions if we overexpressed $R P B 7$ the need for Rpb4p to stabilize the interaction could be eliminated. This possibility is depicted in the third panel. To test this model, we overexpressed $R P B 7$ to various levels in a haploid $r p b 4 \Delta$ strain and tested if temperature sensitivity (ts) and slow-growth phenotypes associated with $r p b 4 \Delta$ are rescued. We also expressed $R P B 4$ from the corresponding vectors as positive control and observed complete rescue of the two phenotypes as expected (data not shown). Figure 2

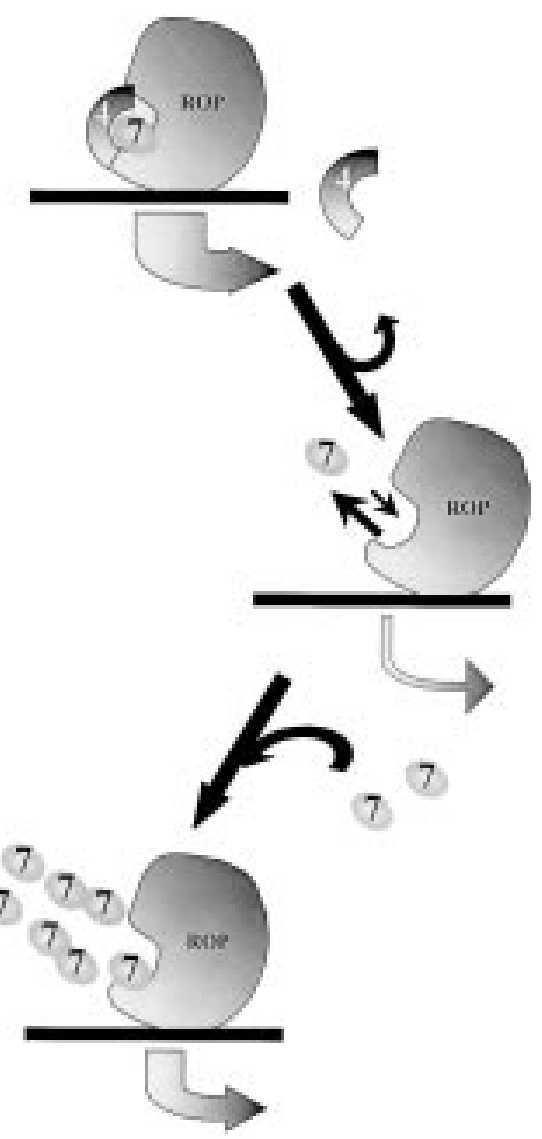

Figure 1. The model representing the Rpb4p-stabilized interaction between Rpb7p and the rest of the Pol II (ROP) and its effect on transcription. The top part shows the situation in the wild type while the second and third parts represent the rpb4 $\Delta$ strain. In all the parts the core polymerase consisting of 12 subunits is shown above the horizontal line, which represents the DNA, while the right-pointing arrow under the horizontal line represents the level of transcription (thickness of arrow). For clarity, the Rpb4/7 subcomplex has been shown much larger than its size in relation to ROP. See text for explanation. 
(a)
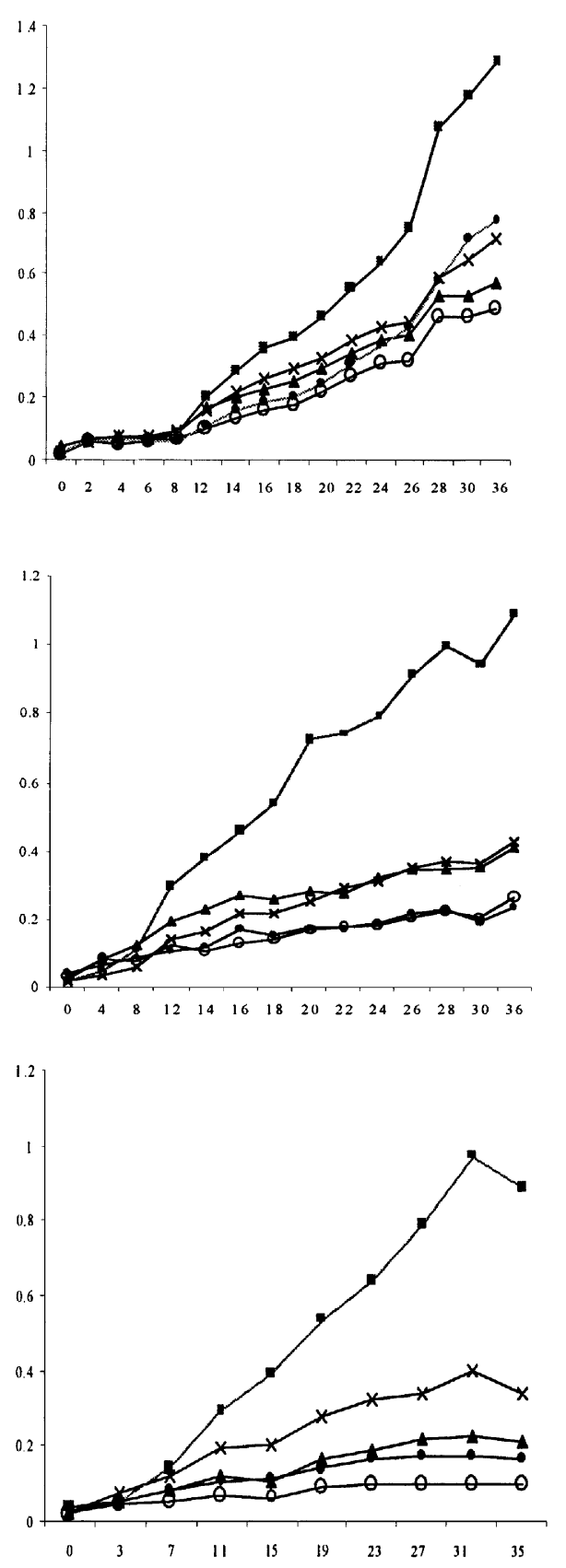

Glucose
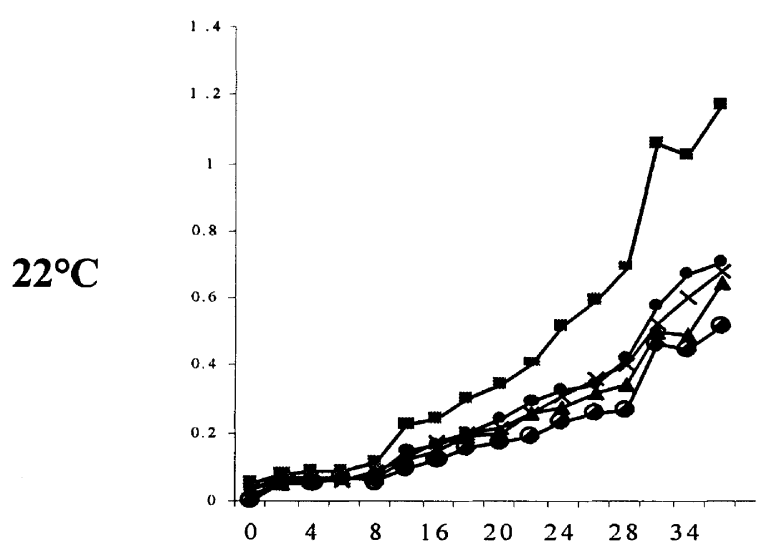

$34^{\circ} \mathrm{C}$

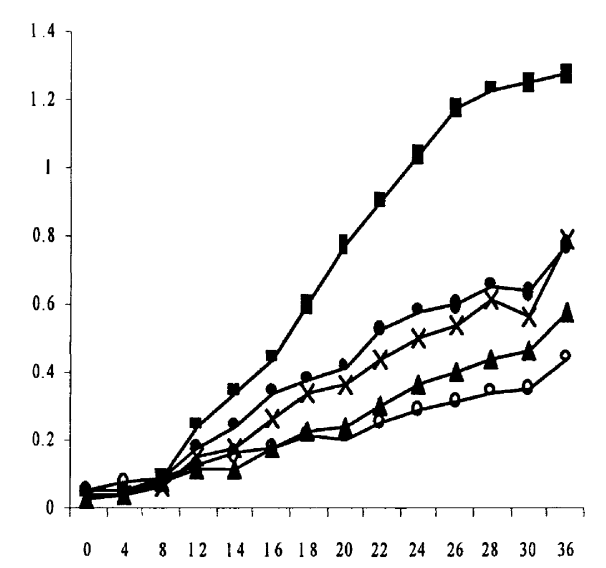

$37^{\circ} \mathrm{C}$

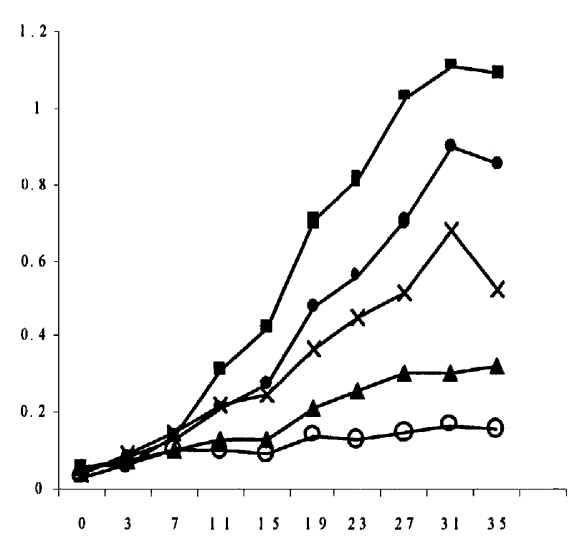

Galactose

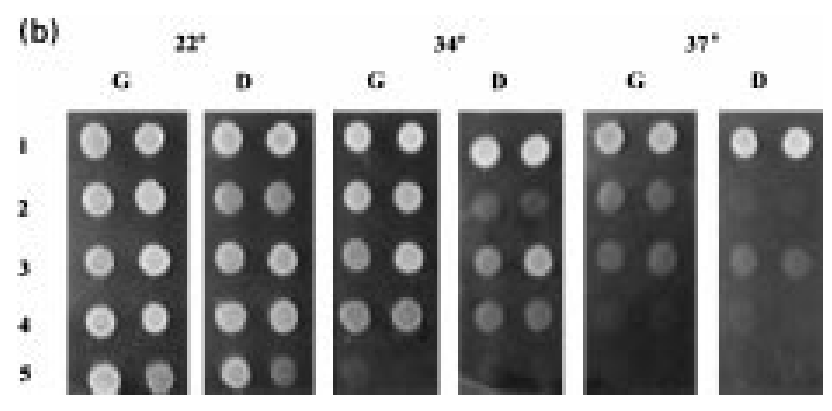




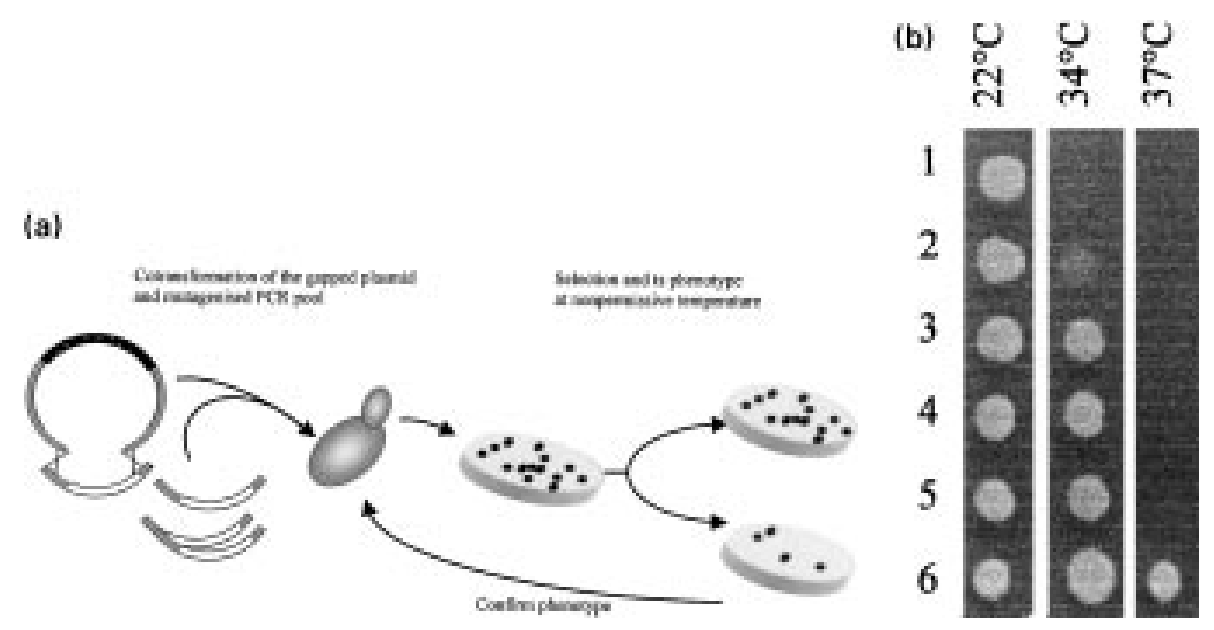

Figure 3. Dominant mutants of $R P B 7$ allow growth at higher temperature in absence of Rpb4p. (a) Screen for mutants: The $r p b 4 \Delta$ strain was transformed with a pool of PCR-mutagenized RPB7 gene fragment along with gapped plasmid pBP86 containing the $5^{\prime}$ and $3^{\prime}$ untranslated regions of the gene. Only in vivo recombination between the PCR product and the gapped plasmid will generate a complete plasmid, which will give rise to transformants. For further details, see the Materials and methods section. (b) Rescue of temperature sensitivity of $r p b 4 \Delta$ strain in $R P B 7$ mutants. The mutants and control strains were spotted on SD media and incubated at the permissive and nonpermissive temperatures. Numbers 1 to 6 are $r p b 4 \Delta, r p b 4 \Delta+$ pRA56, rpb4 $\Delta+$ mut \#3, rpb4 $\Delta+$ mut \#22, rpb4 $\Delta+$ pPS26 and $r p b 4 \Delta+$ pNS114.

shows the rescue of both the slow growth and the temperature sensitivity of $r p b 4 \Delta$ cells harbouring various plasmids carrying the $R P B 7$ open reading frame under its own or GAL1 promoter control. At a nonpermissive temperature, e.g. $34^{\circ} \mathrm{C}, R P B 7$ on a multicopy plasmid (in SY106) appears to rescue both the phenotypes to significant extent. At the higher nonpermissive temperature, $37^{\circ} \mathrm{C}$, the difference between the strains overproducing Rpb7p under GAL1 control (SY107) and the parent $r p b 4 \Delta$ strain (SY101) is very pronounced. The growth curves show that in glucose, when $R P B 7$ expression under GAL1 promoter is not induced, leaky expression from this promoter allows rescue of temperature sensitivity to some extent (figure $2 a$ ). Figure $2 b$ also shows that the $r p b 4 \Delta$ strain does not survive at $34^{\circ} \mathrm{C}$ but the same strain carrying the $R P B 7$ gene on a $2 \mu$ plasmid does and so does the strain carrying RPB7 under the GAL1 promoter control in noninducing condition. We tested the levels of transcript corresponding to the $R P B 7$ open reading frame (ORF) in all the above cases. It was found that as the level of $R P B 7$ transcript increased, greater extent of rescue of the ts and slow-growth phenotypes was achieved. The observation that $R P B 7$ overexpression rescues the $r p b 4 \Delta$ phenotype in a dose-dependent manner suggests that, at the least, one of the roles of Rpb4p is to stabilize the interaction of Rpb7p with the core polymerase, as proposed in the model above (figure 1).

\section{Dominant mutants of RPB7 eliminate the need for Rpb4p at nonpermissive temperature}

On the basis of the above results we proposed that it should be possible to obtain dominant mutants of $R P B 7$ that are presumably improved in their interaction with RNA Pol II and therefore can dispense with the requirement for Rpb4p even when the mutant $R P B 7$ is expressed at relatively low levels. As seen above $R P B 7$ expressed on a single-copy plasmid does not rescue the ts phenotype associated with $r p b 4 \triangle$. We reasoned that if a mutant $R P B 7$ ORF in the context of its own untranslated regions on the same plasmid could rescue the phenotype, this could be most likely due to better interaction of the mutant Rpb7p with core Pol II, a situation similar to the wild-type gene expressed at higher levels. We achieved this by transforming the $r p b 4 \Delta$ strain with a pool of PCR-mutagenized $R P B 7$ along with a gapped CEN plasmid vector (pBP86) containing the untranslated upstream and downstream regions of $R P B 7$ (figure 3a).

Figure 2. Temperature sensitivity and slow growth rate of $r p b 4 \Delta$ strain is rescued by overexpression of $R P B 7$. (a) Growth curves show differences in growth rate of $r p b 4 \Delta$ cells with different levels of $R P B 7$ expression. The $r p b 4 \Delta$ strain SY101 (- $\bigcirc-)$ grows slowly at moderate $\left(22^{\circ} \mathrm{C}\right)$ temperature and does not grow at elevated $\left(34^{\circ} \mathrm{C}\right.$ or $\left.37^{\circ} \mathrm{C}\right)$ temperatures in comparison with the $R P B 4$ strain

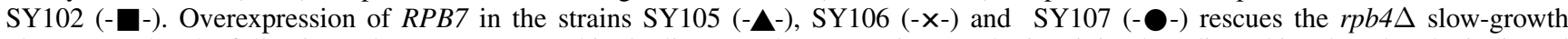
phenotype. (b) The following cultures were spotted in duplicate on the appropriate synthetic minimal media and incubated at the indicated temperatures. The carbon source in the medium is indicated above each panel $(\mathrm{G}=$ galactose, $\mathrm{D}=\mathrm{glucose})$. In each panel, numbers 1 to 5 are strains SY102, SY107 (RPB7 ORF under GAL1 promoter control), SY106 (RPB7 gene on a multicopy plasmid), SY105 (RPB7 gene on a single-copy plasmid), and SY101. 
Recombination in vivo between the PCR product and the gapped plasmid generates a complete circular plasmid with mutagenized $R P B 7 \mathrm{ORF}$ in the context of wild-type upstream and downstream regions on a single-copy plasmid. Out of the 500 transformants that were tested for their ability to grow at the nonpermissive temperature of $34^{\circ} \mathrm{C}$ about 100 were reproducibly shown to have the expected phenotype. Plasmids from transformants showing the best rescue were recovered and reintroduced into the parent strain. These transformants, which reproducibly showed the expected phenotypes, were considered to harbour the mutants of interest. Figure $3 \mathrm{~b}$ shows a typical temperature-sensitivity test at this stage in the screen. Two mutant plasmids (numbers 3 and 22) introduced into the $r p b 4 \Delta$ strain confer on the $r p b 4 \Delta$ cells as good an ability to survive at the nonpermissive temperature of $34^{\circ} \mathrm{C}$ as the $R P B 7$ wild-type gene on a multicopy plasmid (pPS26); this is in contrast to the growth ability conferred by the single-copy pRA56 carrying the $R P B 7$ wild-type gene. The plasmids carrying these mutant $R P B 7$ were sequenced. This revealed that both the mutants cause an identical, $\mathrm{Thr} \rightarrow$ Ala change at amino acid position 28 . We are in the process of confirming the phenotypes of the two mutants by recreating mutations at the specific residue by site-directed mutagenesis.

\section{Morphology of haploid S. cerevisiae is altered significantly on overexpression of RPB7 in rpb4 $\triangle$ background}

One of the stress-related phenotypes of $S$. cerevisiae that has been characterized in great detail is the pseudohyphal growth exhibited by diploid cells in response to nitrogen starvation. The pseudohyphal growth is typified by cell elongation along with unipolar budding. The buds remain attached to the mother cells forming long columns of cells. Several mutations that enhance the sensing of severity of nitrogen starvation and several components of signal transduction pathways as well as transcriptional regulators have been described (Banuett 1998). Contrary to earlier suggestions that the phenotype is specific to diploids, it was observed that even haploids are able to show similar phenotypes with somewhat elongated cells that remain attached to each other. To distinguish this haploid phenotype the pattern has been referred to as agar-invasive growth (Gimeno et al. 1993).

It had been observed earlier that overexpression of $R P B 7$ and its human homologue in diploid cells predisposed to form pseudohyphae caused a highly exaggerated pseudohyphal phenotype in response to low-nitrogen conditions (Khazak et al. 1995). We monitored the morphology of haploid rpb4 $\triangle$ strains overexpressing $R P B 7$ to various extents (described above). Both $r p b 4 \triangle$ and $R P B 4$ wild type exhibit axial budding pattern with normal yeast cell morphology. Even the rpb4 $\Delta$ derivatives containing the $R P B 7$ gene on either the CEN or $2 \mu$ plasmid or the RPB7 ORF under GAL1 promoter (grown under noninducing conditions) showed similar morphology (data not shown). Interestingly, the $r p b 4 \Delta$ strain overexpressing $R P B 7$ under the highly inducible GAL1 promoter showed the pseudohyphal phenotype (figure 4). The photographs in figure 4 show the morphology of $r p b 4 \triangle$ cells carrying either $R P B 4$ on a CEN plasmid or RPB7 ORF under GAL1 promoter control. The cells overexpressing $R P B 7$ in galactose show markedly elongated cells. One of us (P. P. S.) had previously shown that the wild type (RPB4) overexpressing $R P B 7$ under $G A L 1$ promoter exhibits normal yeast morphology (Khazak et al. 1995). We also expressed $R P B 4$ in the rpb4 $\Delta$ strain already overexpressing $R P B 7$ and found that the morphology returns to normal yeast type (data not shown).

\section{Comparison of transcripts from rpb4 $\triangle$ and RPB4 strains by RAP-PCR}

Since the phenotypes observed in the absence of $R P B 4$ were so different from those observed in its presence, it was obvious that the two strains should have significant qualitative and/or quantitative differences in their patterns of gene expression. Since this difference is expected to be at the transcriptional level, we used the RAP-PCR technique to compare the transcripts expressed in $r p b 4 \Delta$ cells with the transcripts from $R P B 4$ cells grown at $22^{\circ} \mathrm{C}$. The analysis was repeated several times to confirm reproducibility of the pattern observed. One autoradiograph showing a typical pattern is presented in figure 5. The RNAs were analysed using five different arbitrary primers and the products generated were compared. All the five primers used show differences in the transcriptional pattern between the two strains. It was interesting to see that there were products representing many specific transcripts upregulated in either $R P B 4$ or $r p b 4 \triangle$ cells. The observation thus indicates that presence of $R P B 4$ may regulate the expression of certain genes positively and that of others negatively and affects the overall transcriptional pattern in cells. Analysis of these

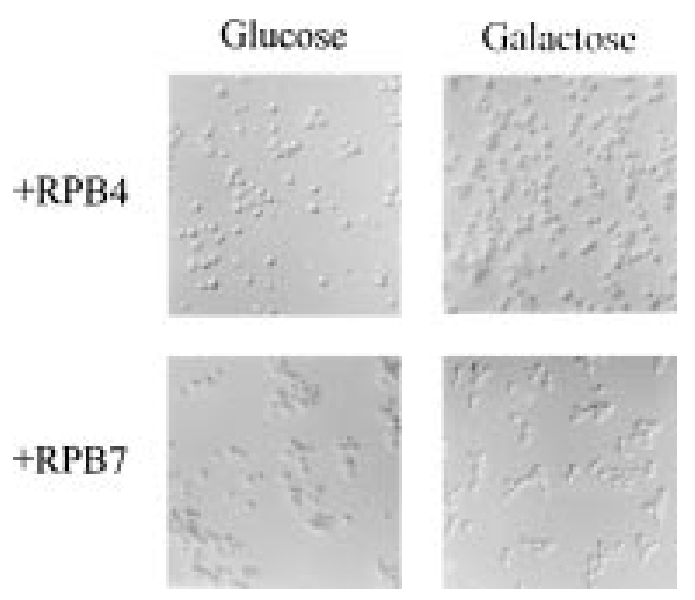

Figure 4. Overexpression of $R P B 7$ affects cell morphology in $r p b 4 \Delta$ haploids. The cells were observed at $400 \times$ using Nomarski optics during growth at $22^{\circ} \mathrm{C}$ (represented in figure 2a). The sugar present in the medium and the gene introduced on plasmid are indicated. The photographs show the cells at about 22 hours of growth. 


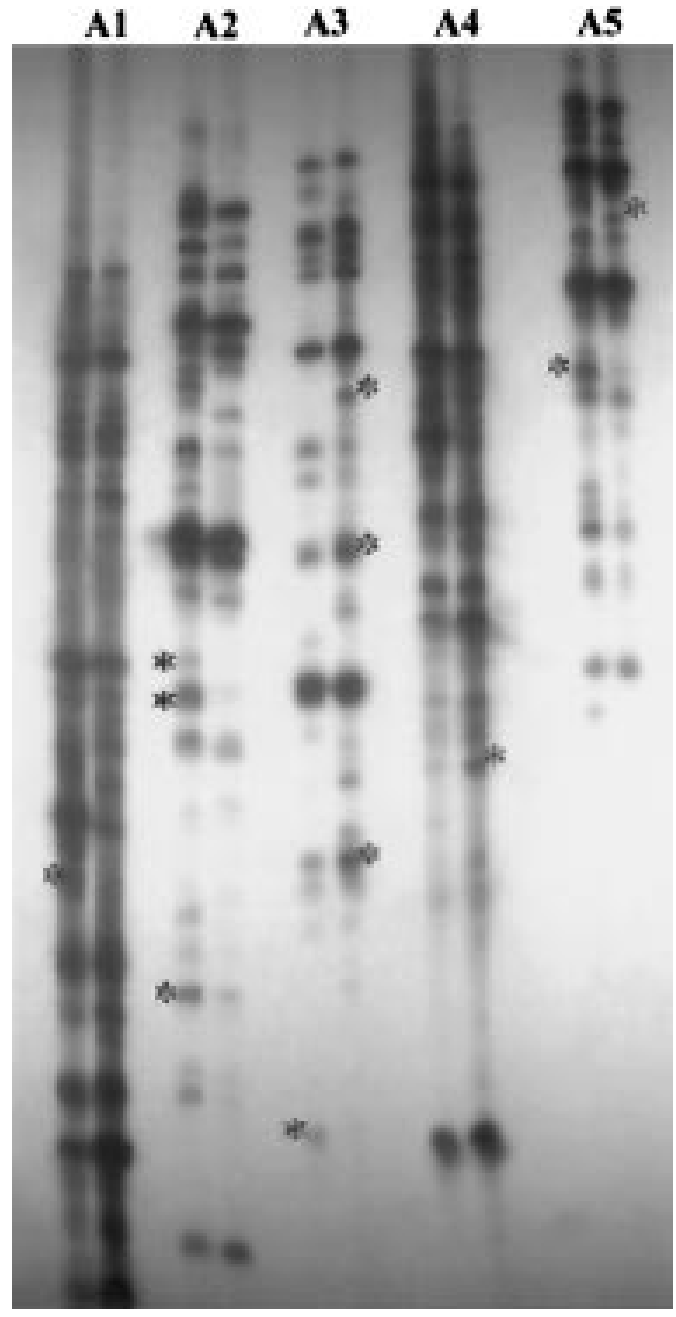

Figure 5. Differences in transcriptional pattern in $r p b 4 \Delta$ and $R P B 4$ cells are evident in RAP-PCR analysis of total RNA. A typical result of RAP-PCR analysis of RNAs from $R P B 4$ and $r p b 4 \Delta$ strains is shown. In each pair of lanes the left lane is $r p b 4 \Delta$ and the right lane $R P B 4$. The label above each pair (A1 to A5) indicates the arbitrary primer used for RAP-PCR. The bands corresponding to differentially expressed transcripts are marked with an asterisk next to the lane showing increased level of transcript. See Materials and methods for details.

differentially regulated genes is currently in progress. It will enable us to identify the mediators of this regulation.

\section{Discussion}

We started our investigations by proposing the hypothesis that one of the two nonessential subunits, Rpb4, of yeast RNA Pol II could play a role in stabilizing the interaction between the essential subunit Rpb7 and the rest of Pol II even under non-stress conditions (Sadhale et al. 1998).

Here we have shown by two different approaches, namely (a) overexpression studies and (b) dominant-mutant analyses, that at least one of the roles of Rpb4 is indeed to stabilize the interaction between $\mathrm{Rpb} 7 \mathrm{p}$ and the rest of the polymerase. The fact that $\mathrm{Rpb} 7 \mathrm{p}$ rescues defects associated with lack of its interacting partner $\mathrm{Rpb} 4 \mathrm{p}$ in a dose-dependent manner also supports our model shown in figure 1. Our observations that dominant mutants of $R P B 7$ rescue temperature sensitivity better than the wildtype subunit, at equivalent levels, corroborate the above results. Although this is not the only explanation one of the testable mechanisms by which these dominant mutants could act is by interacting more strongly with the rest of the polymerase.

It has been reported that $\mathrm{Rpb} 4$ has a role in stabilizing the polymerase during stress implying that in the absence of Rpb4p RNA Pol II becomes mechanically unstable under stress conditions (Mckune et al. 1993). Overexpression of $R P B 7$ has been recently shown to rescue certain phenotypes of $r p b 4 \Delta$ but the possibility of the role of Rpb4p in stabilizing the interaction between $\mathrm{Rpb} 7 \mathrm{p}$ and the rest of the polymerase under moderate conditions has been overlooked (Rosenhech and Choder 1998; Sheffer et al. 1999). Our results suggest that even under moderate conditions Rpb7 requires Rpb4 to interact effectively with the rest of the polymerase.

The overall transcription pattern analyses using RAPPCR indicate that lack of Rpb4p does not lead to a mere ubiquitous lowering of transcription but causes more qualitative changes as well. This implies that there is more to the function of the two proteins $R p b 4 p$ and Rpb7p in the subcomplex of Pol II. We suggest that Rpb4p not only plays a role in stabilizing the interaction between $\mathrm{Rpb} 7$ and the rest of the polymerase but also a more direct role in mediating interactions with specific transcriptional regulators, which in turn drive expression of specific genes under moderate conditions. We suspect that Rpb7p is involved in some interactions that are masked in the presence of Rpb4p. On the other hand, in combination with Rpb4p, alternative protein-protein interactions are possible. Thus by altering the levels of these two subunit polypeptides functionally, the cell may actually be able to regulate the above interactions and in turn produce different phenotypes.

Our results now allow us to present a different perspective on the role played by the Rpb4/7 subcomplex in affecting stress responses in yeast. On the basis of our results we predict that $r p b 4 \Delta$ cells show defects in transcription of several genes owing to altered protein-protein interactions in absence of Rpb4p. The associated stress response defects are probably an indirect effect on the expression of stressresponse genes. This suggestion is in agreement with other observations reported in the literature but differs from most interpretations in that it confers on the Rpb4 subunit a more active role in transcription of stress-related genes (Maillet et al. 1999). Our results support the notion that the smaller subunits of core RNA polymerase II can actually play a regulatory role rather than a passive role as originally thought (Woychik and Young 1989). We propose that modulation of the relative levels of the two subunits could be one way to regulate gene expression in yeast. 


\section{Acknowledgements}

We are grateful to the rest of the lab, especially P. Beena and Vinaya Sampath, for helpful discussions and critical comments. We would like to thank Aparna Katoch for carrying out the RPB7 dominant mutant screen. This work was supported by Department of Science and Technology and Council for Scientific and Industrial Research grants to P. P. S.

\section{References}

Ausubel F. M., Brent R., Kingston R., Moore D., Seidman, J., Smith J. A. and Struhl K. 1987-1994 Current protocols in molecular biology. Wiley, New York.

Banuett F. 1998 Signaling in the yeasts: an informational cascade with links to the filamentous fungi. Microbiol. Mol. Biol. Rev. 62, 249-274.

Choder M. 1993 A growth rate-limiting process in the last growth phase of the yeast life cycle involves $R P B 4$, a subunit of RNA polymerase II. J. Bacteriol. 175, 6358-6363.

Choder M. and Young R. A. 1993 A portion of RNA polymerase II molecules has a component essential for stress response and stress survival. Mol. Cell. Biol. 13, 6984-6991.

Edwards A. M., Kane C. M., Young R. A. and Kornberg R. D. 1991 Two dissociable subunits of yeast RNA polymerase II stimulate the initiation of transcription at a promoter in vitro. $J$. Biol. Chem. 266, 71-75.

Elble R. 1992. A simple and efficient procedure for transformation of yeasts. Biotechniques 13, 18-20.

Geitz R. D. and Sugino A. 1988 New yeast-Escherichia coli shuttle vectors constructed with in vitro mutagenised yeast genes lacking six base pair restriction sites. Gene 74, 527-534.

Gimeno C. J., Ljungdahl P. O., Styles C. A. and Fink G. R. 1993 Characterisation of Saccharomyces cereviseae pseudohyphal growth. In Dimorphic fungi in biology and medicine (ed. H. Vanden Bossche), pp. 83-103. Plenum, New York.

Hampsey M. 1998 Molecular genetics of the RNA polymerase II general transcription machinery. Microbiol. Mol. Biol. Rev. 62, 465-503.

Ishihama A., Kimuri M. and Motsuzawa H. 1998 Subunits of yeast RNA polymerases: Structure and function. Curr. Opin. Microbiol. 1, 190-196.
Khazak V, Sadhale P. P., Woychik N. A., Brent R. and Golemis E. A. 1995 Human RNA polymerase II subunit hsRPB7 functions in yeast and influences stress survival and cell morphology. Mol. Biol. Cell 6, 759-765.

Mckune K., Richards K. L., Edwards A. M., Young R. A. and Woychik N. A. 1993 RPB7, one of two dissociable subunits of yeast RNA polymerase II, is essential for cell viability. Yeast $\mathbf{9}$, 295-299.

Maillet I., Buhler J. M., Sentenac A. and Labarre J. 1999 Rpb4p is necessary for RNA polymerase II activity at high temperature. $J$. Biol. Chem. 274, 22586-22590.

Miyao T. and Woychik N. A. 1998 RNA polymerase subunit RPB5 plays a role in transcriptional activation. Proc. Natl. Acad. Sci. USA 95, 15281-15286.

Rosenhech S. and Choder M. 1998 Rpb4, a subunit of RNA polymerase II, enables the enzyme to transcribe at temperature extremes in vitro. J. Bacteriol. 180, 6187-6192.

Ruet A., Sentenac A., Fromageot P., Winsor B. and Lacroute F. 1980 A mutation of the B220 subunit gene affects the structural and functional properties of yeast RNA polymerase B in vitro. $J$. Biol. Chem. 255, 6450-6455.

Sadhale P. P. and Woychik N. A. 1994 C25, an essential RNA polymerase III subunit related to the RNA polymerase II subunit RPB7. Mol. Cell. Biol. 14, 6164-6170.

Sadhale P. P., Sharma N., Beena P., Katoch A, Acharya N. and Singh S. K. 1998 Modulation of polymerase II composition: a possible mode of transcriptional regulation of stress response in eukaryotes. J. Biosci. 23, 331-335.

Scafe C., Nonet M. and Young R. A. 1990 RNA polymerase II mutants defective in transcription of a subset of genes. Mol. Cell. Biol. 10, 1010-1016.

Sheffer A., Varon M. and Choder M. 1999 Rpb7 can interact with RNA polymerase II and support transcription during some stresses independently of Rpb4. Mol. Cell. Biol. 19, 2672-2680.

Sherman F., Fink G. R. and Hicks J. B. 1983 Methods in yeast genetics. Cold Spring Harbor Laboratory Press, Cold Spring Harbor.

Vijayraghavan U., Company M. and Abelson J. 1989 Isolation and characterisation of pre-mRNA splicing mutants of $S$. cerevisiae. Genes Dev. 3, 1206-1216.

Woychik N. A. and Young R. A. 1989 RNA polymerase II subunit RPB4 is essential for high and low temperature yeast cell growth. Mol. Cell. Biol. 9, 2854-2859. 